\title{
PENERAPAN METODE MODIFIED DISTRIBUTION (MODI) DALAM MEMINIMALISASI BIAYA TRANSPORTASI PENGIRIMAN BARANG DI PT. TIRTA MAKMUR PERKASA
}

\author{
Risnawati Ibnas ${ }^{\mathrm{i}}$, Wahida Alwii ${ }^{\mathrm{ii}}$, Achmad Taufik ${ }^{\mathrm{iii}}$
}

${ }^{i}$ Universitas Islam Negeri Alauddin Makassar, risnawati.ibnas@uin-alauddin.ac.id

${ }^{i i}$ Universitas Islam Negeri Alauddin Makassar,wahida.alwi@uin-alauddin.ac.id

iii Universitas Islam Negeri Alauddin Makassar, achmadtaufiq45@yahoo.com

\begin{abstract}
ABSTRAK, Distribusi dapat diartikan sebagai proses penyaluran barang atau jasa dari produsen ke konsumen. Untuk menyalurkan barang suatu perusahaan, maka diperlukan alat transportasi dan biaya distribusi untuk mengirim barang tersebut dengan menggunakan alat transportasi. Dalam suatu masalah transportasi, misalnya pada PT. Tirta Makmur Perkasa dapat dibentuk menjadi suatu model transportasi. Model transportasi dapat diselesaikan dengan 2 tahap yaitu solusi awal dengan Vogel's Approximation Method (VAM) dan solusi akhir dengan metode Modified Distribution (MODI). Penelitian ini bertujuan untuk mendapatkan biaya transportasi PT. Tirta Makmur Perkasa. Hasil penelitian menunjukkan bahwa biaya transportasi minimum pada PT. Tirta Makmur Perkasa pada bulan Sepetember sampai Desember 2016 dengan menggunakan metode Vogel's Approximation Method sebagai solusi awal dan Metode Modified distribution (MODI) diperoleh nilai sebesar Rp $72.697 .634,4$
\end{abstract}

Kata Kunci : Transportasi, Vogel's Approximation Method, Metode Modified Distribution.

\section{PENDAHULUAN}

Distribusi dapat diartikan sebagai proses penyaluran barang atau jasa dari sumber (produsen) ke tujuan (konsumen). Untuk menyalurkan barang suatu perusahaan, maka diperlukan alat transportasi (berupa transportasi pribadi atau transportasi umum/sewa) dan biaya distribusi dalam meyalurkan barang tersebut. Salah satu faktor yang dapat mempengaruhi keuntungan suatu perusahaan adalah dengan meminimkan biaya transportasi tanpa menghambat penjualan dalam menyalurkan barang dari sumber ke tujuan.

Masalah transportasi terjadi ketika perusahaan mencoba menentukan cara pengiriman suatu jenis barang dari beberapa sumber ke beberapa tujuan untuk meminimumkan biaya. Pengiriman barang ini harus diatur sedemikian rupa karena terdapat perbedaan biaya pengiriman dari satu sumber ke tempat tujuan yang berbeda, dan dari beberapa sumber ke suatu tempat tujuan agar biaya taransportasi dapat lebih minimum.

Perusahaan yang menjadikan model transportasi sebagai alat strategi akan mempunyai keunggulan dalam merebut persaingan dangan perusahaan perusahaan lain yang sejenis. PT. Tirta Makmur Perkasa merupakan perusahaan yang memproduksi air minum dalam kemasan (Air Mineral Club) dalam jumlah yang sangat besar. Adapun air mineral dalam kemasan yang diproduksi yaitu AMDK Club 19 lt, 1500 ml, $600 \mathrm{ml}, 330 \mathrm{ml}$ dan $240 \mathrm{ml}$. Dalam medistribusikan barangnya ke beberapa daerah, PT. Tirta Makmur Perkasa menggunakan kendaraan pribadi milik perusahaan. Dalam pendistribusian menggunakan kendaraan pribadi, pendistribusian dilakukan langsung kebeberapa tujuan suplayer yang tersebar dibeberapa daerah Sulawesi Selatan. Dalam pendistribusian barangnya, PT. Tirta Makmur Perkasa yang kadang kala mengalami pembengkakan biaya distribusi, hal ini terjadi dikarenakan metode pendistribusian yang digunakan saat ini dengan menggunakan metode pendistribusian langsung. Pendistribusian dari pabrik ketempat tujuan dengan jarak yang berbeda beda mengakibatkan anggaran biaya distribusi juga berbeda beda. Oleh sebab itu dibutuhkan upaya untuk menekan biaya distribusi dengan selalu memperhatikan beberapa biaya tak terduga dan dibutuhkan suatu perencanaan dan teknik perhitungan yang matang agar biaya transportasi yang dikeluarkan seminimum mungkin.

Beberapa metode penyelesaian fisibel awal dari model transportasi diantaranya North West Corner (NWC), Biaya terendah (least cost) dan Metode Vogel's Approximation Method (VAM), selanjutnya melakukan uji untuk 
mendapatkan solusi optimum. Solusi optimum dapat diperoleh dengan 2 menggunakan metode Stepping Stone dan Metode Modified Distribution (MODI)."

Pada Penelitian ini menggunakan metode Vogel's Aproximation Method (VAM) sebagai langkah solusi awal dan selanjutkan menggunakan Metode Modified Distribution (MODI) sebagai langkah solusi optimal model transportasi pada PT. Tirta Makmur Perkasa khusus pendistribusian AMDK $240 \mathrm{ml}$ area Sulawesi Selatan.

\section{TINJAUANPUSTAKA}

\section{Riset Operasi}

Riset operasi mencakup dua kata yaitu riset yang harus menggunakan metode ilmiah dan operasi yang berhubungan dengan proses atau berlangsungnya suatu kegiatan (proses produksi, proses pengiriman barang). Jadi riset yang dilakukan terhadap suatu proses atau berlangsungnya suatu kegiatan yang dilakukan unit organisasi. Suatu proses kegiatan dilakukan untuk mencapai tujuan atau mencapai output yang paling baik, dengan menggunakan masukan (input) yang dalam prakteknya serba terbatas. Dalam keadaan serba terbatas itulah harus dicapai suatu pemecahan yang optimum.

\section{Model Transportasi}

Model Transportasi adalah suatu metode yang digunakan untuk mengatur distribusi suatu produk (barang-barang) dari sumber-sumber yang menyediakan produk (misalnya pabrik), ke tempat-tempat tujuan (misalnya gudang) secara optimal. Tujuan dari model ini adalah menentukan jumlah yang harus dikirim dari setiap sumber ke setiap tujuan sedemikian rupa dengan total biaya transportasi minimum. Suatu model transportasi dikatakan seimbang (balanced program) apabila total jumlah antara penawaran (supply) dan permintaan (demand) sama, secara matematis ditulis:

$$
\sum_{i=1}^{m} a_{i}=\sum_{j=1}^{n} b_{j}
$$

Suatu model transportasi dapat dirumuskan sebagai berikut :

$$
\begin{gathered}
Z_{\text {min }}=\sum_{i=1}^{m} x_{i j}=\sum c_{i j} x_{i j} \\
\sum_{i=1}^{m} x_{i j}<a_{i} ; i \\
=1,2,3, \ldots m \text { (batasan penawaran }) \\
\sum_{i=1}^{m} x_{i j}<b_{j} ; j \\
=1,2,3, \ldots m(\text { batasan permintaan }) \\
\text { Ketrangan : } \\
X_{i j}=\begin{array}{l}
\text { Unit yang dikirim dari sumber } i \text { ke } \\
\text { tujuan } j
\end{array} \\
C_{i j}=\begin{array}{l}
\text { Biaya per unit dari sumber } i \text { ke } \\
\text { tujuan } j
\end{array} \\
a_{i}=\begin{array}{l}
\text { Kapasitas penawaran (supply) dari } \\
\text { sumber } i
\end{array} \\
b_{i}=\text { Kapasitas permintaan (demand) dari } \\
\text { tujuan } j \\
i=1,2, \ldots, m ; j=1,2, \ldots, n
\end{gathered}
$$

Bila kapasitas sama dengan permintaan maka seluruh batasan berupa persamaan. Bila kapasitas lebih besar dari permintaan maka batasan sumber berupa pertidaksamaan dengan tanda " $\leq$ " dan bila kapasitas lebh kecil dari permintaan maka batasan tujuan berupa pertidaksamaan " $\geq$ ". Penggunaan pertidak samaan ini mempunyai 3 tujuan untuk mengalokasikan kelebihan kapasitas yang terjadi kedalam dummy.

\section{Metode Pemecahan Transportasi}

Metode Vogel's Approximation Method (VAM) Dalam penentuan solusi awal, VAM menetapkan konsep denda (penalty cost). Denda dimaksudkan sebagai selisih antar dua biaya terkecil pada selsel yang sebaris/sekolom. Pengerjaan metode VAM adalah sebagai berikut:

a. Tentukan denda untuk setiap baris dan kolom dengan mengurungkan dua biaya terkecil pada sel-sel yang sebaris atau sekolom (selisih antar dua biaya terkecil pada setiap baris atau kolom). b. Pilih baris 
atau kolom dengan memuat denda tertinggi (atau memilih sel dengan biaya terkecil).

b. Alokasikan sebesar mungkin pada sel fisibel dengan biaya transportasi terkecil dalam baris atau kolom dengan denda terbesar.

c. Ulangi langkah-langkah 1, 2, dan 3 sampai tercapai suatu solusi biaya minimum.

\section{Metode Modified Distribution (MODI)}

Metode MODI tidak lain dari algoritma batu loncatan (Stepping Stone) dengan teknik yang sudah diperhalus untuk menghitung indeks yang akan ditingkatkan. Perbedaan antara kedua cara ini terletak pada langkah-langkah yang digunakan untuk menyelesaikan persoalan yang mana terdapat jejak tertutup yang akan ditelusuri. Metode MODI menghitung indeksi yang akan ditingkatkan ialah tanpa menggambarkan semua jejak tertutup. Cara MODI cukup menelusuri satu saja jejak tertutup. Sama seperti pada batu loncatan, dalam cara MODI dengan aturan pojok barat laut. Pengoperasian metode MODI dalam menyelesaikan masalah transportasi, prinsip dasarnya sama dengan metode yang lain. Untuk mencari nilai sel bukan baris berdasarkan metode MODI, dilakukan dengan cara menambahkan suatu baris katakanlah $K j$ yang menyatakan nilai setiap kolom $K_{1,2}, K_{3}, \ldots K_{j}$ dan menyatakan satu kolom katakanlah $R i$ yang menyatakan nilai setiap baris $R_{1}, R_{2}, R_{3}, \ldots \ldots R_{i}$. Nilai $K_{j}$ dan $R_{i}$ yang dicari hanya untuk sel baris (jumlah sel basis sama dengan $m+n-1$ ), dengan menggunakan rumus $\mathrm{R}_{\mathrm{i}}+\mathrm{K}_{\mathrm{j}}=\mathrm{C}_{\mathrm{ij}}=$ biaya angkut per satuan dari tempat asal (i) ke tempat tujuan (j). Sedangkan untuk mencari nilai sel bukan basis yang digunakan rumus $\mathrm{Cij}$ - $\mathrm{R}_{\mathrm{i}}-\mathrm{K}_{\mathrm{j}}$, langkah awal metode MODI dapat dimulai dari tabel awal metode NW-Corner maupun tabel awal metode biaya minimum.

Tabel Awal Metode Transportasi

\begin{tabular}{|c|c|c|c|c|c|c|}
\hline \multirow{2}{*}{\multicolumn{2}{|c|}{$\mathrm{Dari}_{\text {Dari }} \mathrm{Ke}$}} & \multicolumn{4}{|c|}{ Tujuan } & \multirow{3}{*}{$\begin{array}{c}\begin{array}{c}\text { Penawaran } \\
\text { (supply) }\end{array} \\
a_{1}\end{array}$} \\
\hline & & 1 & 2 & $\ldots$ & $\mathrm{n}$ & \\
\hline \multirow{4}{*}{ 晃 } & 1 & $c_{11}$ & $c_{12}$ & & $c_{1 n}$ & \\
\hline & 2 & $c_{21}$ & $c_{22}$ & & & $a_{2}$ \\
\hline & $\ldots$ & $\ldots$ & $\ldots$ & $\ldots$ & $\ldots$ & $\ldots$ \\
\hline & $\mathrm{m}$ & $c_{m 1}$ & $c_{m 2}$ & & $c_{m n}$ & $a_{m}$ \\
\hline \multicolumn{2}{|c|}{$\begin{array}{c}\text { Permintaan } \\
\text { (demand) }\end{array}$} & $b_{1}$ & $b_{2}$ & $\cdots$ & $b_{n}$ & \\
\hline
\end{tabular}

$X_{i j}=$ Unit yang dikirim dari sumber $i$ ke tujuan $j$

$C_{i j}=$ Biaya per unit dari sumber $i$ ke tujuan $j$

$a_{i}=$ Kapasitas penawaran (supply) dari sumber $i$

$b_{i}=$ Kapasitas permintaan (demand) dari tujuan $j$

$$
\begin{aligned}
i & =1,2, \ldots, m \\
j & =1,2, \ldots, n
\end{aligned}
$$

\section{METODOLOGI}

Data rekam medis dari salah satu rumah sakit di Sulawesi Selatan renang waktu tahun 2014 hingga 2015 menjadi obyek dari analisis survive yang berkaitan dengan penyakit kanker payudara. Variabel yang diperhatikan adalah lama waktu rawat inap pasien (hari) dengan faktor-faktor yang mempengaruhinya dari variabel independent, diantaranya-faktor usia, stadium klinis-I (Ca-Mammae), II (Tumor Mammae), III (Tumor Mamme Multiple dan hepatitis), IV (Tumor Mammae Post dan Post $O P)$.

\section{Prosedur Analisis}

1. Mengumpulkan data perusahaan yang berkaitan dengan alokasi produk, yaitu biaya distribusi produk dari sumber ke tujuan $\left(C_{i j}\right)$, kapasitas masing-masing gudang, dan permintaan produk dimasing-masing tujuan.

2. Memasukkan data yang telah dikumpulkan kedalam tabel awal transportasi.

3. Menyelesaikan table awal dengan Vogel's Aproximation Method.

4. Memperoleh solusi awal model transportasi

5. Tabel akhir pada solusi awal model transportasi dengan syarat $m-n+1$, dengan $\mathrm{m}$ adlah jumlah baris dan $\mathrm{n}$ adalah jumlah kolom.

6. Selanjutnya diselesaikan dengan solusi optimal Modified Distribution.

7. Memperoleh hasil optimal biaya transportasi.

Keterangan : 


\section{HASIL}

PT. Tirta Makmur Perkasa merupakan perusahaan yang bergerak dalam bidang suplay air minum dalam kemasan yakni air mineral Club. Perusahaan ini mempunyai beberapa mobil kontainer sebagai alat angkut dari beberapa pabrik ke tempat tujuan distribusi.

Perusahaan ini mempunyai dua pabrik yaitu di Kab. Takalar dan Kab. Gowa dengan kapasitas yang berbeda-beda. Kapasitas dari masingmasing gudang dapat dilihat pada tabel berikut:

Tabel 4.1.1: Kapasitas Setiap Pabrik PT. Tirta Makmur Perkasa

\begin{tabular}{|c|c|}
\hline Gudang & Kapasitas (box) \\
\hline Gowa & 155.567 \\
\hline Takalar & 99.073 \\
\hline Jumlah & $\mathbf{2 5 4 . 6 4 0}$ \\
\hline
\end{tabular}

Tabel 4.1.2 :Permintaan Setiap Tujuan Distribusi pada Bulan September -

\begin{tabular}{|c|c|c|c|c|c|c|c|}
\hline No. & $\begin{array}{c}\text { Bulan } \\
\text { pendistribusian }\end{array}$ & $\begin{array}{c}\text { S.Yusuf } \\
\text { (box) }\end{array}$ & $\begin{array}{r}\text { Kima } \\
\text { (box) }\end{array}$ & $\begin{array}{c}\text { Maros } \\
\text { (box) }\end{array}$ & $\begin{array}{l}\text { Pangkep } \\
\text { (box) }\end{array}$ & $\begin{array}{c}\text { Barru } \\
\text { (box) }\end{array}$ & $\begin{array}{c}\text { Pare- } \\
\text { pare } \\
\text { (box) }\end{array}$ \\
\hline 1. & September & 43.881 & 15.576 & 1.800 & 2.158 & 4.872 & 3.950 \\
\hline 2. & Oktober & 42.400 & 17.430 & 1.410 & 3.050 & 2.470 & 1.950 \\
\hline 3. & November & 31.927 & 20.622 & 1.570 & 2.395 & 4.385 & 1.600 \\
\hline 4. & Desember & 33.160 & 8.400 & 400 & 1.759 & 4.555 & 2.920 \\
\hline \multicolumn{2}{|r|}{ Total } & \begin{tabular}{|l|}
151.368 \\
\end{tabular} & 62.028 & 5.180 & 9.362 & 16.282 & 10.420 \\
\hline
\end{tabular}

Tabel 4.1.3: Distribusi PT. Tirta Makmur Perkasa pada bulan September - Desemb 2016

\begin{tabular}{|c|c|c|c|c|c|c|c|} 
Tujuan & $\begin{array}{c}\text { Syech } \\
\text { Yusuf } \\
\text { Sumber }\end{array}$ & $\begin{array}{c}\text { Kima } \\
\text { (box) }\end{array}$ & $\begin{array}{c}\text { Maros } \\
\text { (box) }\end{array}$ & $\begin{array}{c}\text { Pangkep } \\
\text { (box) }\end{array}$ & $\begin{array}{c}\text { Barru } \\
\text { (box) }\end{array}$ & $\begin{array}{c}\text { Pare- } \\
\text { pare } \\
\text { (box) }\end{array}$ & Kapasit: \\
\hline Gowa & 93.470 & 40.503 & 3.070 & 4.307 & 9.967 & 4.250 & $\mathbf{1 5 5 . 5 6}$ \\
\hline Takalar & 57.898 & 21.525 & 2.110 & 5.055 & 6.315 & 6.270 & $\mathbf{9 9 . 0 7 3}$ \\
\hline Permintaan & $\mathbf{1 5 1 . 3 6 8}$ & $\mathbf{6 2 . 0 2 8}$ & $\mathbf{5 . 1 8 0}$ & $\mathbf{9 . 3 6 2}$ & $\mathbf{1 6 . 2 8 2}$ & $\mathbf{1 0 . 4 2 0}$ & $\mathbf{2 5 4 . 6 4 1}$ \\
\hline
\end{tabular}

Biaya yang dikeluarkan oleh PT. Tirta Makmur Perkasa untuk pengiriman barang ketempat tujuan yakni terhitung dari pabrik ke tempat tujuan. Perusahaan ini melakukan pengiriman barang AMDK Club dengan ukuran yang berbeda-beda (19 lt, $1500 \mathrm{ml}, 600 \mathrm{ml}, 330 \mathrm{ml}$, dan $240 \mathrm{ml}$ ) ke tempat tujuan dengan rincian biaya sebagai berikut:

1. Gowa ke Syech Yusuf = Rp 40.000,- per container

2. Gowa ke Kima $=$ Rp.75.000,- per container

3. Gowa ke Maros = Rp 115.000,- $\quad$ per container

4. Gowa ke Pangkep $=\operatorname{Rp} 178.000,-$ per container
5. Gowa ke Barru $=\operatorname{Rp} 461.000,-$ per container

6. Gowa ke Pare-pare $=\operatorname{Rp} 550.000,-$ per container

7. Takalar ke Syech Yusuf $=$ Rp 63.000,- per container

8. Takalar ke Kima $=\operatorname{Rp} 95.000,-$ per container

9. Takalar ke Maros $=\quad \mathrm{Rp} \quad$ 135.000,-per container

10. Takalar ke Pangkep $=\mathrm{Rp}$ 236.000,per container

11. Takalar ke Barru $=\mathrm{Rp}$ 570.000,per container

12. Takalar ke Pare-pare $=\mathrm{Rp} 882.000$,per container

Tabel 4.1.4: Biaya Distribusi Per-Unit dari Setiap Sumber (Gudang) ke Setiap Tujuan

\begin{tabular}{|c|c|c|c|c|c|c|} 
Tujuan & $\begin{array}{c}\text { Syech } \\
\text { Yusuf } \\
\text { Sumber } \\
(\mathbf{R p} / \mathbf{b o x})\end{array}$ & $\begin{array}{c}\text { Kima } \\
(\mathbf{R p} / \mathbf{b o x})\end{array}$ & $\begin{array}{c}\text { Maros } \\
(\mathbf{R p} / \mathbf{b o x})\end{array}$ & $\begin{array}{c}\text { Pangkep } \\
(\mathbf{R p} / \mathbf{b o x})\end{array}$ & $\begin{array}{c}\text { Barru } \\
(\mathbf{R p} / \mathbf{b o x})\end{array}$ & $\begin{array}{c}\text { Pare-pare } \\
(\mathbf{R p} / \mathbf{b o x})\end{array}$ \\
\hline Gowa & 50,50 & 170,36 & 449,51 & 743,90 & 1526,34 & 1423,53 \\
\hline Takalar & 126,22 & 353,08 & 1535,55 & 1680,71 & 4061,76 & 4717,34 \\
\hline
\end{tabular}

Fungsi Tujuan :

$Z=\sum_{i=1}^{2} \sum_{j=1}^{6} C_{i j} X_{i j}$

$=C_{11} X_{11}+C_{12} X_{12}+C_{13} X_{13}+C_{14} X_{14}+C_{15} X_{15}+C_{16} X_{16}+C_{21} X_{21}+$

$C_{22} X_{22}+C_{23} X_{23}+C_{24} X_{24}+C_{25} X_{25}+C_{26} X_{26}$

$=50,50 X_{11}+170,36 X_{12}+449,51 X_{13}+743,90 X_{14}+1526,34 X_{15}+$ $1423,53 X_{16}+126,22 X_{21}+353,08 X_{22}+1535,55 X_{23}+1680,71 X_{24}+$ $4061,76 X_{25}+4717,34 X_{26}$

(4.1)

Tabel 4.1.5: Total Keseluruhan Biaya Distribusi PT. Tirta Makmur Perkasa pada

\begin{tabular}{|c|c|c|c|c|}
\hline Sumber & Tujuan & $\begin{array}{c}\text { Jumlah } \\
\text { (box) }\end{array}$ & $\begin{array}{c}\text { Biaya Distribusi } \\
\text { (Rp/box) }\end{array}$ & $\begin{array}{l}\text { Biaya Total } \\
\text { (Rp) }\end{array}$ \\
\hline \multirow{6}{*}{ Gowa } & Syech Yusuf & 93.470 & 50,50 & 4.720 .235 \\
\hline & Kima & 40.503 & 170,36 & $6.900 .091,08$ \\
\hline & Maros & 3.070 & 449,51 & $1.379 .995,7$ \\
\hline & Pangkep & 4.307 & 743,90 & $3.203 .997,3$ \\
\hline & Barru & 9.967 & 1526,34 & $15.213 .030,78$ \\
\hline & Pare-pare & 4.250 & 1423,53 & 6.049 .960 \\
\hline \multirow{6}{*}{ Takalar } & Syech Yusuf & 57.898 & 126,22 & $7.307 .885,56$ \\
\hline & Kima & 21.525 & 353,08 & 7.600 .047 \\
\hline & Maros & 2.110 & 1535,55 & $3.240 .010,5$ \\
\hline & Pangkep & 5.055 & 1680,71 & $8.495 .989,05$ \\
\hline & Barru & 6.315 & 4061,76 & $25.650 .014,4$ \\
\hline & Pare-pare & 6.170 & 4717,34 & $29.105 .987,8$ \\
\hline \multicolumn{4}{|c|}{ Total } & Rp 118.867.220 \\
\hline
\end{tabular}

$Z=\sum_{i=1}^{2} \sum_{j=1}^{6} c_{i j} X_{i j}$

$=C_{11} X_{11}+C_{12} X_{12}+C_{13} X_{13}+C_{14} X_{14}+C_{15} X_{15}+C_{16} X_{16}+C_{21} X_{21}+$

$C_{22} X_{22}+C_{23} X_{23}+C_{24} X_{24}+C_{25} X_{25}+C_{26} X_{26}$

$=50,50 X_{11}+170,36 X_{12}+449,51 X_{13}+743,90 X_{14}+1526,34 X_{15}+$ $1423,53 X_{16}+126,22 X_{21}+353,08 X_{22}+1535,55 X_{23}+1680,71 X_{24}+$ $4061,76 X_{25}+4717,34 X_{26}$

$=74.690 .885,7$ 
Batasan-batasan :

$$
\begin{aligned}
& X_{11}+X_{12}+X_{13}+X_{14}+X_{15}+X_{16}=155.567 \\
& X_{21}+X_{22}+X_{23}+X_{24}+X_{25}+X_{26}=99.073 \\
& X_{11}+X_{21}=151.368 \\
& X_{12}+X_{22}=62.028 \\
& X_{13}+X_{23}=5.180 \\
& X_{14}+X_{24}=9.362 \\
& X_{15}+X_{25}=16.282 \\
& X_{16}+X_{26}=10.420
\end{aligned}
$$

\begin{tabular}{|c|c|c|c|c|c|c|c|}
\hline $\begin{array}{l}\text { Tujuan } \\
\text { Sumber }\end{array}$ & SY & K & M & $\mathbf{P}$ & B & PP & Kapasitas \\
\hline & 50,50 & 170,36 & 449,51 & 743,90 & 1526,34 & 1423,53 & \\
\hline Gowa & 52.295 & 62.028 & 5.180 & 9.362 & 16.282 & 10.420 & $\mathbf{1 5 5 . 5 6 7}$ \\
\hline Takalar & $\begin{array}{c}126,22 \\
99.073\end{array}$ & $\begin{array}{l}353.08 \\
0^{2}\end{array}$ & $\begin{array}{l}1535,55 \\
0\end{array}$ & $\begin{array}{l}1680,71 \\
0\end{array}$ & $\begin{array}{l}4061,76 \\
0\end{array}$ & $\begin{array}{l}4717,34 \\
0\end{array}$ & 99.073 \\
\hline Permintaan & 151.368 & 62.028 & 5.180 & 9.362 & 16.282 & 10.420 & 254.640 \\
\hline
\end{tabular}

Tabel solusi Awal

\begin{tabular}{|c|c|c|c|c|c|c|c|}
\hline Tujuan & SY & $\mathbf{K}$ & $\mathbf{M}$ & $\mathbf{P}$ & $\mathbf{B}$ & $\mathbf{P P}$ & Kapasitas \\
\hline Sumber & 50,50 & 170,36 & 449,51 & 743,90 & 1526,34 & 1423,53 & $\mathbf{1 5 5 . 5 6 7}$ \\
Gowa & $x_{11}$ & $x_{12}$ & $x_{13}$ & $x_{14}$ & $x_{15}$ & $x_{16}$ & \\
\hline \multirow{2}{*}{ Takalar } & 126,22 & 353.08 & 1535,55 & 1680,71 & 4061,76 & 4717,34 & $\mathbf{9 9 . 0 7 3}$ \\
& $x_{21}$ & $x_{22}$ & $x_{23}$ & $x_{24}$ & $x_{25}$ & $x_{26}$ & \\
\hline Permintaan & $\mathbf{1 5 1 . 3 6 8}$ & $\mathbf{6 2 . 0 2 8}$ & $\mathbf{5 . 1 8 0}$ & $\mathbf{9 . 3 6 2}$ & $\mathbf{1 6 . 2 8 2}$ & $\mathbf{1 0 . 4 2 0}$ & $\mathbf{2 5 4 . 6 4 0}$ \\
\hline
\end{tabular}

Pengalokasian menggunakan Metode VAM

terlihat bahwa seluruh kebutuhan baris dan kolom sudah terpenuhi yang berarti solusi awal. Selanjutnya menghitung total biaya minimum

\begin{tabular}{|c|c|c|c|c|c|c|c|}
\hline$\overbrace{\text { Sumber }}^{\text {Tujuan }}$ & $\underset{K_{i}=50,50}{S Y}$ & $\begin{array}{c}\mathrm{K} \\
K_{2}=170,36\end{array}$ & $\begin{array}{c}\mathbf{M} \\
K_{3}=449,51\end{array}$ & $\begin{array}{c}\mathbf{P} \\
K_{1}=743,90\end{array}$ & \begin{tabular}{c|c}
$\mathbf{B}$ \\
$K_{5}=1526,34$
\end{tabular} & $\begin{array}{c}\text { PP } \\
K_{6}=1423,53\end{array}$ & Kapasitas \\
\hline $\begin{array}{l}\text { Gowa } \\
R_{1}=0\end{array}$ & $\begin{array}{r}50,50 \\
52.295 \\
\end{array}$ & $\begin{array}{r}170,36 \\
62.028\end{array}$ & $\begin{array}{r}449,51 \\
5.180 \\
\end{array}$ & $\begin{array}{r}\quad 743,90 \\
9.362\end{array}$ & $\begin{array}{r}1526,34 \\
16.282\end{array}$ & $\begin{array}{c}1423,53 \\
10.420 \\
\end{array}$ & $\mathbf{1 5 5 . 5 6 7}$ \\
\hline $\begin{array}{l}\text { Takalar } \\
R_{2}=75,72\end{array}$ & $\begin{array}{c}126,22 \\
99.073\end{array}$ & $0^{353.08}$ & $0^{1535,55}$ & $0^{1680,71}$ & $0^{4061,76}$ & $0^{4717,34}$ & 99.073 \\
\hline Permintaan & 151.368 & 62.028 & 5.180 & 9.362 & 16.282 & 10.420 & 254.640 \\
\hline
\end{tabular}
distribusi :

\section{Solusi Otimum}

\begin{tabular}{|c|c|c|c|c|c|c|c|}
\hline $\mathrm{S}_{\text {Sumber }}^{\text {Tujuan }}$ & $\underset{\substack{\text { SY } \\
K_{t}=50,50}}{\text { SY }}$ & \begin{tabular}{|c|}
$\mathbf{K}$ \\
$K_{2}=170,36$
\end{tabular} & $\begin{array}{c}\mathbf{M} \\
K_{3}=449,51\end{array}$ & $\underset{K_{4}=743,90}{\mathbf{P}}$ & $\begin{array}{c}\text { B } \\
K_{5}=1526,34\end{array}$ & $\begin{array}{c}\text { PP } \\
K_{6}=1423,53 \\
\end{array}$ & Kapasitas \\
\hline Gowa & 50,50 & 170,36 & 449,51 & 743,90 & 1526,34 & 1423,53 & \\
\hline$R_{1}=0$ & 52.295 & 62.028 & 5.180 & 9.362 & 16.282 & 10.420 & $\mathbf{1 5 5 . 5 6 7}$ \\
\hline $\begin{array}{l}\text { Takalar } \\
R_{2}=75,72\end{array}$ & 126,22 & 353.08 & 1535,55 & 1680,71 & 4061,76 & 4717,34 & 99.073 \\
\hline Permintaan & 151.368 & 62.028 & 5.180 & 9.362 & 16.282 & 10.420 & 254.640 \\
\hline
\end{tabular}

Sebelum dilakukan pengujian optimalisasi lebih lanjut maka banyaknya sel yang yang terpenuhi harus memnuhi syarat $=(m+n)-1=$ $(2+6)-1=7$.

\section{Metode MODI}

Table akhir solusi optimal metode MODI

$$
\begin{aligned}
Z= & \sum_{i=1}^{2} \sum_{j=1}^{6} C_{i j} X_{i j} \\
= & C_{11} X_{11}+C_{12} X_{12}+C_{13} X_{13}+C_{14} X_{14}+C_{15} X_{15}+C_{16} X_{16}+C_{21} X_{21}+ \\
& C_{22} X_{22}+C_{23} X_{23}+C_{24} X_{24}+C_{25} X_{25}+C_{26} X_{26} \\
= & 50,50 X_{11}+170,36 X_{12}+449,51 X_{13}+743,90 X_{14}+1526,34 X_{15}+ \\
& 1423,53 X_{16}+126,22 X_{21}+353,08 X_{22}+1535,55 X_{23}+1680,71 X_{24}+ \\
& 4061,76 X_{25}+4717,34 X_{26} \\
= & 74.690 .885,7
\end{aligned}
$$

Dengan demikian hasil yang diperoleh dari dengan menggunakan metode MODI, yaitu sebesar Rp 74.690.885,7 .

\section{PEMBAHASAN}

Dalam hal ini langkah-langkah untuk mendapatkan solusi awal dengan menggunkan Metode Vogel's Approximation Method (VAM) diperoleh total biaya distribusi sebesar Rp. 74.690.885,7.

Untuk mendaptakan hasil paling minimum dilakukan perhitungan menggunakan prosedur Metode Modified Distribution (MODI) sebagai solusi optimum, dengan langkah-langkah sesuai dengan prosedur penelitian.

Setelah menemukan nilai indeks pada baris dan kolom $\quad\left(\quad K_{1}=50,50, K_{2}=170,36, K_{3}=\right.$ $449,51, K_{4}=743,90, K_{5}=1526,34, K_{6}=$ $1423,53, R_{1}=0, R_{2}=75,72$. Kemudian mencari sel yang kosong yakni terdapat pada sel Takalar-Kima $\left(I_{22}\right)$, Takalar-Maros $\left(I_{23}\right)$, Takalar-Pangkep $\left(I_{24}\right), \quad$ Takalar-Barru $\left(I_{25}\right)$, Takalar - Pare-pare $\left(I_{26}\right)$. Setelah sel yang kosong ditemukan, kemudian menghitung nilai pada sel kosong tersebut dengan rumus $\left(I_{i j}=\right.$ $C_{i j}-R_{i}-K_{j}$ ) sehingga diperoleh: 


$$
\begin{aligned}
I_{22}=C_{22}- & R_{2}-K_{2} \\
& =353,08-75,72-170,36 \\
& =107
\end{aligned}
$$

$I_{23}=C_{23}-R_{2}-K_{3}=1535,55-75,72-$ $449,51=1010,32$

$I_{24}=C_{24}-R_{2}-K_{4}=1680,71-75,72-$ $743,90=861.09$

$I_{25}=C_{25}-R_{2}-K_{5}=4061,76-75,72-$ $1526,34=2459,69$

$I_{26}=C_{26}-R_{2}-K_{6}=4717,34-75,72-$ $1423,53=3218,09$

Dalam perhitungan sel-sel kosong tersebut tidak ditemukan nilai negatif (penghematan biaya) berarti solusi optimum telah diperoleh. Selanjutnya menghitung nilai total biaya minimum distribusi dengan menggunakan persamaan (4.1) sehingga diperoleh hasil $\mathrm{Rp}$ 74.690.885,7.

Dengan demikian proses untuk mencari hasil optimum dengan menggunakan metode Modified Distribution (MODI) telah selesai, dimana hasil yang diproleh sama dengan hasil yang diperoleh dengan menggunakan Metode Vogel's Approximation Method (VAM).

Jadi hasil yang diperoleh dari metode Modified Distribution (MODI) sudah optimum.

\section{KESIMPULAN}

Kesimpulan dari hasil penelitian ini adalah sebagai berikut:

1. Total biaya distribusi minimum denagn menggunakan Vogel's Approximation Method (VAM) sebagai solusi awal pada PT. Tirta Makmur Perkasa yaitu sebesar Rp 74.690.885,7.

2. Total biaya distribusi optimal dengan Modified Distribution Method (MODI) yaitu sebesar Rp 74.690.885,7 ,-.

\section{DAFTAR PUSTAKA}

[1] Aminuddin. Prinsip-Prinsip Riset Operasi. Jakarta. Erlangga. 2005

[2] Gede, I. Penerapan Metode Modified Distribution Dalam Sistem Pendistribusian Barang Pada PT. Miswak
Utama. Jurnal Teknik Informatika Vol. 3 No. 4, 2008.

[3] Liberman, Gerald j. Pengantar Riset Operasi. Erlangga. Jakarta. 1990.

[4] Permata Sari, Desi. Optimasi Distribusi Gula Merah Pada UD sari Bumi Menggunakan Model Transportasi dan Model Least Cost. Sistem Informasi Vol. 3 No.2. 2010.

[5] Putri. Nurjuliawati. Aplikasi Steppring Tone Untuk Optimalisasi Perencenaan biaya Pada suatu Proyek Kontruksi. Jurnal Sipil Statik Vol 1 No.8. Juli 2013.

[6] Sarjono. Haryadi. Aplikasi Riset Operasi . [7] Salemba Empat. Jakarta. 2010.

[8] Sari, J.K. Penyelesaian Persoalan Transportasi dengan Kendala campuran. 2010.

[9] Sasmito, Agus. Visualisasi Teori Optimalisasi Biaya Transportasi Untuk Pembelajaran Riset Operasi. Jurusan Teknik Informatika UPN "Vetran" Yogyakarta. Vol. 3 No. 1. 2010.

[10] Soenarjo. Al-Qur'an dan terjemahan. Yayasan Penyelenggara penerjemah/penafsir Al-Qur' an. Jakarta. 1971.

[11] Suprapto, J. Riset Operasi Untuk Pengambilan Keputusan. Universitas Indonesia (UI). 1998

[12] Situmorang, Marihat. Aplikasi Metode Transportasi dalam meminimalisai Biaya Distribusi Beras Miskin (Raskin) Pada Perum Bulog Sub Drive Medan. Jurnal Sintia Matematika. Vol. 02. No. 03. 2014.

[13] Tarliah, Tjutu. Operation Research (Model-Model Pengambilan Keputusan). Bandung: Sinar Batu Algesindo. 2006.

[14] Yuwono, Bambang . Bahan Kuliah Riset operasional. UPN Yoktakarta. Yogyakarta. 2007.. 